\title{
Variation in summer nitrogen and phosphorus uptake among Siberian headwater streams
}

\author{
John D. Schade, ${ }^{1}$ Erin C. Seybold, ${ }^{2}$ Travis Drake, ${ }^{3}$ Seth Spawn, ${ }^{4}$ William V. Sobczak, ${ }^{5}$ Karen E. Frey, ${ }^{6}$
} Robert M. Holmes ${ }^{4}$ \& Nikita Zimov ${ }^{7}$

${ }^{1}$ Environmental Studies Department, St. Olaf College, 1520 St. Olaf Avenue, Northfield, MN 55057, USA

2 Nicholas School of the Environment, Duke University, PO Box 90328, Durham, NC 27708, USA

${ }^{3}$ Environmental Studies Program, University of Colorado, 1201 17th Street, Boulder, CO 80309, USA

${ }^{4}$ Wood Hole Research Center, 149 Woods Hole Road, Falmouth, MA 02540, USA

${ }^{5}$ Biology Department, College of the Holy Cross, 1 College Street, Worcester, MA 01610, USA

${ }^{6}$ Department of Geography, Clark University, 950 Main Street, Worcester, MA 01610, USA

${ }^{7}$ Northeast Science Station, P.O. Box 18, Cherskiy, Sakha Republic, Russia

\section{Keywords}

Arctic streams; nutrient uptake; hydrologic transient storage; phosphorus sorption; coupled $\mathrm{N}$ and $\mathrm{P}$ cycling.

\section{Correspondence}

John D. Schade, Environmental Studies Department, St. Olaf College, 1520 St, Olaf Avenue, Northfield, MN 55057, USA. E-mail: schade@stolaf.edu

\begin{abstract}
Arctic streams are likely to receive increased inputs of dissolved nutrients and organic matter from thawing permafrost as climate warms. Documenting how Arctic streams process inorganic nutrients is necessary to understand mechanisms that regulate watershed fluxes of permafrost-derived materials to downstream ecosystems. We report on summer nitrogen $(\mathrm{N})$ and phosphorus (P) uptake in streams draining upland soils from the Pleistocene, and lowland floodplain soils from the Holocene, in Siberia's Kolyma River watershed. Uptake of $\mathrm{N}$ and $\mathrm{P}$ differed between upland and floodplain streams, suggesting topographic variation in nutrient limitation. In floodplain streams, $\mathrm{P}$ uptake rate and uptake velocity were higher than $\mathrm{N}$, while upland streams had similar values for all $\mathrm{N}$ and $\mathrm{P}$ uptake metrics. Phosphorus uptake velocity and size of the transient hydrologic storage zone were negatively related across all study streams, indicating strong influence of hydrologic processes on nutrient fluxes. Physical sorption of $\mathrm{P}$ was higher in floodplain stream sediments relative to upland stream sediments, suggesting more physically driven uptake in floodplain streams and higher biological activity in upland streams. Overall, these results demonstrate that high-latitude headwater streams actively retain $\mathrm{N}$ and $\mathrm{P}$ during summer base flows; however, floodplain and upland streams varied substantially in $\mathrm{N}$ and $\mathrm{P}$ uptake and may respond differently to inorganic nutrient and organic matter inputs. Our results highlight the need for a comprehensive assessment of $\mathrm{N}$ and $\mathrm{P}$ uptake and retention in Arctic streams in order to fully understand the impact of permafrost-derived materials on ecosystem processes, and their fate in continental drainage networks.
\end{abstract}

To access the supplementary material for this article, please see the supplementary files under Article Tools, online.
In the coming century, anthropogenic climate warming is predicted to be amplified in the Arctic relative to lower latitudes (Symon et al. 2005). Arctic amplification (Serreze \& Francis 2006; Screen \& Simmonds 2010) will likely lead to globally significant consequences, including the thawing of permafrost soils that underlay many Arctic ecosystems (Schuur et al. 2008; Schaefer et al. 2011). These soils are generally rich in organic matter and represent a significant pool of labile carbon and other nutrients, which have been stored for thousands of years (Zimov et al. 2006; Tarnocai et al. 2009). This is particularly true in north-east Siberia, where permafrost 


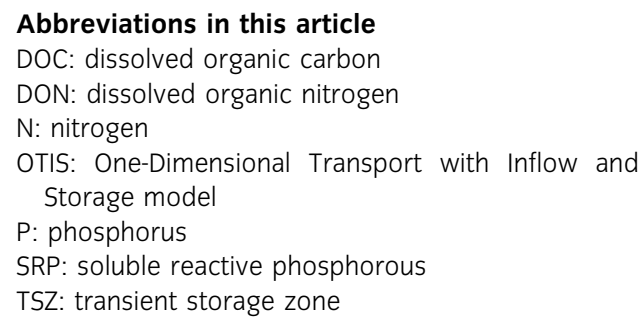

soils are composed of frozen organic-rich loess deposits, which will release a significant amount of highly-labile carbon and nutrients upon thaw (Vonk et al. 2013). Small, first-order streams will receive these materials, owing to their unique position linking upland terrestrial environments to larger rivers and coastal oceans, and therefore have the potential to regulate the export of carbon, $\mathrm{N}$ and $\mathrm{P}$ to downstream ecosystems (Alexander et al. 2000; Wollheim et al. 2001). Arctic streams have received insufficient attention to date, particularly in eastern Siberia, and an improved understanding of their role in the landscape is essential to assessing the impact of permafrost thaw on nutrient export to the ocean.

Recent studies of Arctic rivers have shown a consistent seasonal pattern in which concentration and bioavailability of organic matter and nutrients is high during spring thaw, followed by a substantial decline in the summer (Holmes et al. 2008; Mann et al. 2012), with most nutrient flux to the ocean occurring during spring snow melt (Finlay et al. 2006; Holmes et al. 2008; Mann et al. 2012). These studies, however, have focused on temporal dynamics at the mouths of these rivers, and we still do not know where or how the signal observed at river mouths is generated within watersheds. One possible explanation is that organic matter and nutrient inputs from terrestrial ecosystems may be lower and more refractory in the summer as hydrologic connections between terrestrial ecosystems and headwater streams decrease, leading to observed low concentrations in summer. Alternatively, low summer export of nutrients from large rivers may indicate a shift to active processing of nutrient inputs by small streams during summer months, when stream discharge decreases and temperatures rise. Furthermore, during these months, small streams have high potential to alter nutrient fluxes because there is significant contact between water and the streambed where physical sorption by sediment particles or biological uptake by microbes may remove nutrients from the water column (Alexander et al. 2000; Sobczak \& Findlay 2002). Biological and physical processes in small Arctic streams, therefore, may be playing a larger role in regulating nutrient exports than is generally recognized.
Research on Arctic streams has primarily focused on their metabolic response to $\mathrm{N}$ and $\mathrm{P}$ enrichment, with little attention explicitly paid to rates of $\mathrm{N}$ and $\mathrm{P}$ uptake. Enrichment studies show a range of biological responses, including increased primary and secondary productivity and heterotrophic activity that suggest $\mathrm{P}$ limitation (Peterson et al. 1985; Slavik et al. 2004; Mann et al. 2013). These observed increases in biological activity have been linked to changes in uptake rates of $\mathrm{N}$ and $\mathrm{P}$ in headwater streams that may influence the mass and form of nutrient exports. Few published studies, however, report direct measurements of nutrient uptake rates for Arctic streams, and these have been geographically limited to streams in Alaska (Wollheim et al. 2001; Slavik et al. 2004; Benstead et al. 2005; Greenwald et al. 2008). Comparable studies of streams in the Siberian Arctic are notably absent.

Our objective in this study was to investigate landscape variation in rates of $\mathrm{N}$ and $\mathrm{P}$ uptake, and the relative importance of physical and biological processes that may control nutrient uptake during the summer low-flow period in Arctic streams in eastern Siberia. We studied two classes of streams that varied in topographic position and sediment composition and age. All streams drain subwatersheds of the Kolyma River that are underlain by continuous permafrost. Upland streams drain Pleistoceneaged loess soils, while floodplain streams drain Holoceneaged soils. This comparison will provide information on differences in the relative importance of physical and biological processes relevant to developing hypotheses on how streams in this region may respond to changes in inputs as permafrost thaws.

\section{Methods}

In this study, we applied a whole-ecosystem approach using nutrient spiralling models that explicitly integrate nutrient processing rates and downstream transport (Newbold et al. 1981; Newbold et al. 1983; Newbold 1992). We also investigated the role of physical processes, including transient storage of water within the channel and physical sorption by sediments in regulating nutrient fluxes. Nutrient spiralling provides a conceptual framework and a numerical "toolbox" that ecologists can use to compare the ability of streams to retain and process nutrients and provides a whole-system approach to investigate ecosystem responses to environmental change (Webster \& Patten 1979; Newbold et al. 1981; Ensign \& Doyle 2006; Mulholland et al. 2008; Valett et al. 2008). In this work, we used these tools to assess spatial variation in nutrient processing in Arctic streams and to investigate potential patterns in nutrient limitation across 
the landscape. Nutrient spiralling is quantified in streams using related metrics (summarized in Supplementary Table S1) including uptake length $\left(S_{w}\right)$, uptake rate $(U)$ and uptake velocity (or mass transfer coefficient, $v_{f}$ ). Uptake length is the average distance a nutrient atom travels in a stream before being removed from the water column. Uptake rate represents the area-specific rate of nutrient loss from the water column and is commonly used to compare nutrient demand across streams with differing discharge. Uptake velocity represents the demand for nutrients relative to concentration (Stream Solute Workshop 1990), and allows comparison across streams that differ in discharge and background nutrient concentrations. We also used whole-stream solute additions to estimate transient storage, and chamber nutrient uptake experiments to investigate the relative importance of physical sorption and biological uptake in $\mathrm{P}$ removal from the water column. These experiments are described in greater detail below.

\section{Study site}

Study streams are located in the Kolyma River basin, near the city of Cherskiy in north-east Siberia (Fig. 1). The Kolyma River basin is unique in that it is the largest watershed in the world underlain by continuous permafrost (Zimov et al. 2006; Frey \& McClelland 2009). The climate in this region is dry and continental. Mean annual temperature $(1999-2010)$ is $-9.9^{\circ} \mathrm{C}$, but monthly mean temperatures reach $13.4^{\circ} \mathrm{C}$ in July. Annual precipitation is low, ranging from 200 to $215 \mathrm{~mm} \mathrm{yr}^{-1}$, with only $80-100 \mathrm{~mm}$ falling as rain during the summer months (Corradi et al. 2005). Nutrient spiralling experiments were conducted throughout July 2009 in five headwater streams (one experiment in each), selected based on landscape position and accessibility from the Northeast Science Station. Two (FPS1, FPS2) streams were located in the low-lying floodplain of the Kolyma River, where sediments mainly originate from the Holocene. Three streams (DVY, TDO and Y4) were located topographically higher in the landscape and drained yedoma soils, which date primarily from the Pleistocene. All study streams were quite small (discharge of 1-3 L/s, stream order 1-2, Table 1), with heavily vegetated banks and silty substrates. Bank vegetation was similar between floodplain and upland streams and consisted mainly of sedge tussocks and small woody shrubs.

\section{Whole-stream nutrient uptake}

To quantify nutrient uptake, we conducted whole-stream nutrient release experiments consisting of simultaneous additions of $\mathrm{N}\left(\right.$ as $\left.\mathrm{NH}_{4}^{+}\right)$and $\mathrm{P}\left(\right.$ as $\left.\mathrm{PO}_{4}^{3-}\right)$ with a conservative tracer $\left(\mathrm{Cl}^{-}\right)$to each of the five study streams during summer base flow in July 2009. Our decision to add $\mathrm{N}$ and $\mathrm{P}$ simultaneously was a consequence of

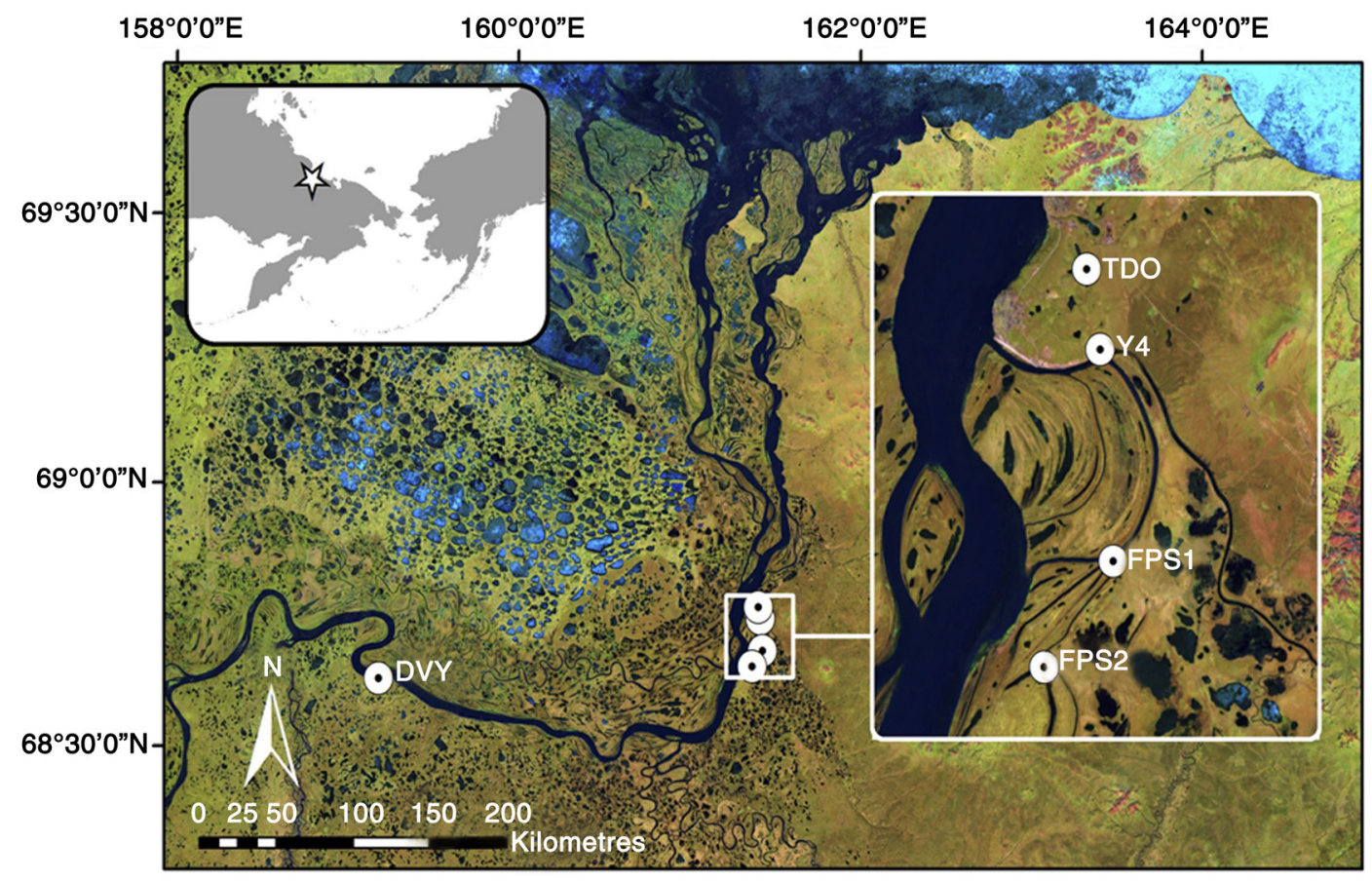

Fig. 1 Map showing location of experimental streams within the Kolyma River watershed in north-eastern Siberia. 
Table 1 Mean background values for relevant physical and chemical variables for the five streams used in this study.

\begin{tabular}{|c|c|c|c|c|c|}
\hline & \multicolumn{3}{|c|}{ Yedoma } & \multicolumn{2}{|c|}{ Floodplain } \\
\hline & DVY & TDO & Y4 & FPS1 & FPS2 \\
\hline \multicolumn{6}{|l|}{ Physical } \\
\hline Discharge $\left(\mathrm{L} \mathrm{s}^{-1}\right)$ & 3.5 & 2 & 1.07 & 3.6 & 2.5 \\
\hline Width (m) & 0.52 & 0.45 & 0.47 & 1.02 & 0.95 \\
\hline Depth (m) & 0.08 & 0.04 & 0.06 & 0.09 & 0.07 \\
\hline Velocity ( $\left.\mathrm{m} \mathrm{s}^{-1}\right)$ & 0.01 & 0.01 & 0.03 & 0.02 & 0.03 \\
\hline Order & 1 & 1 & 2 & 1 & 1 \\
\hline DO \% Sat ${ }^{a}$ & 71.8 & 60.6 & 90.3 & 53.9 & 79.3 \\
\hline Temp (C) & 10.5 & 9.5 & 4.6 & 9.2 & 9.2 \\
\hline Cond $\left(\mu \mathrm{S} \mathrm{m}{ }^{-1}\right)$ & 23 & 27 & 21 & 32 & 35 \\
\hline \multicolumn{6}{|l|}{ Chemical } \\
\hline DOC (mg/L) & 18 & 16.4 & 18.1 & 13 & 14 \\
\hline DON (mg/L) & 0.53 & 0.62 & 0.56 & 0.56 & 0.79 \\
\hline DOC:DON & 39.6 & 36 & 37.7 & 27 & 20.7 \\
\hline $\mathrm{NH}_{4}(\mu \mathrm{g} / \mathrm{L})$ & 21 & 29 & 30 & 18 & 60 \\
\hline $\mathrm{NO}_{3}(\mu \mathrm{g} / \mathrm{L})$ & 10 & 12 & 5 & 9 & 10 \\
\hline $\mathrm{PO}_{4}(\mu \mathrm{g} / \mathrm{L})$ & 13.7 & 32.6 & 34.7 & 9.6 & 18.5 \\
\hline $\mathrm{NH}_{4}: \mathrm{NO}_{3}$ & 2.1 & 2.4 & 6 & 2 & 6 \\
\hline Molar iN:iP & 5 & 2.8 & 2.2 & 6.2 & 8.4 \\
\hline
\end{tabular}

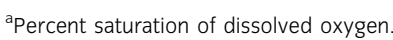

logistical constraints that only allowed one visit to each stream during our field expedition, coupled with the need for information on both $\mathrm{N}$ and $\mathrm{P}$ uptake given uncertainties about nutrient limitation and the impact of future changes in nutrient input from thawing permafrost. We have acknowledged in our previous work (Schade et al. 2011) that this decision has an impact on our interpretation of our results.

Solutes were dissolved in $30 \mathrm{~L}$ of stream water and were added to the surface stream at the top of each reach using a metering pump (Fluid Metering Inc.) at a rate designed to increase nutrient concentrations. In all streams, nutrient enrichments were $<60 \mu \mathrm{g} \mathrm{L}^{-1}$, compared to ca. $100 \mu \mathrm{g} \mathrm{L}^{-1}$ or less typical of previous studies (as reported by Hoellein et al. 2007). Solutes were added at a constant rate until concentrations reached a plateau at all downstream sampling points. Conductivity was measured continuously using YSI 556 multimeters (YSI Incorporated) at the top and bottom of each reach before, during and after solute releases to monitor changes in $\mathrm{Cl}^{-}$for transient storage modelling and to identify when plateau concentrations were reached for nutrient sampling.

In each reach, five transects were established every 10-15 m, depending on total reach length, which varied from 40 to $60 \mathrm{~m}$. Triplicate water samples were collected at each transect prior to the addition and once concentrations reached plateau. All water samples were filtered through Whatman GF/F filters $(0.7 \mu \mathrm{m})$ immediately upon return to the laboratory, and analysed for SRP (an index of $\mathrm{PO}_{4}^{3-}$ ) and ammonium $\left(\mathrm{NH}_{4}^{+}\right)$concentrations at the Northeast Science Station within 24 hours. Subsamples were also frozen for return to St. Olaf College for analysis of nitrate $\left(\mathrm{NO}_{3}^{-}\right)$concentration. Ammonium concentrations were measured using a fluorometric method developed by Holmes et al. (1999) and modified by Taylor et al. (2007) on a Turner Designs Aquafluor portable fluorometer. SRP was measured using the molybdate colorimetric method on a Biotek microplate spectrophotometer. Nitrate was analysed using Cadmium reduction on a Lachat QC8000 Autoanalyzer. Background nutrient concentrations were subtracted from all plateau concentrations to calculate spiralling metrics. All methods had detection limits below $3 \mu \mathrm{g} \mathrm{L}^{-1}$.

Uptake lengths were estimated by regressing logtransformed, background-corrected nutrient concentrations at plateau at each transect against distance downstream (Supplementary Table S1). The inverse of the regression slope is equivalent to the uptake length. Areal nutrient uptake rates and uptake velocity (Supplementary Table S1) were calculated using the equations below:

$$
U=\frac{Q C}{w \cdot S_{W}} \quad V_{f}=\frac{U}{C},
$$

where $U$ is areal uptake rate $\left(\mu \mathrm{g} \mathrm{m}^{-2} \mathrm{~s}^{-1}\right), v_{f}$ is uptake velocity $\left(\mathrm{m} \mathrm{s}^{-1}\right), Q$ is discharge $\left(\mathrm{L} \mathrm{s}^{-1}\right), C$ is background nutrient concentration $\left(\mu \mathrm{g} \mathrm{L}^{-1}\right), w$ is stream width $(\mathrm{m})$ and $S_{W}$ is uptake length $(\mathrm{m})$.

\section{Transient storage modelling}

Transient storage refers to the temporary retention of water and solutes and may occur in small eddies, in stagnant pools, or within the porous sediments below or lateral to the main channel, which together constitute what is referred to as the TSZ. We require estimates of the size of the TSZ and the degree of exchange between it and the main channel to properly understand the fate of solutes, including $\mathrm{N}$ and $\mathrm{P}$, which depend on hydrologic residence time and biological activity of different stream zones (Valett et al. 2008). To characterize hydrologic properties of our sample streams, we applied the OTIS model (Runkel 1998), which has been used to characterize the fate of solutes in a wide range of rivers and streams (Edwardson et al. 2003; Salehin et al. 2003; Ensign \& Doyle 2006; Zarnetske et al. 2007). It comprises a set of mass balance equations for both the main channel, in which solute transport is governed by the advectiondispersion equation, and the TSZ, where advection and 
dispersion are disregarded because downstream transport from these zones is assumed to be negligible (Runkel 1998).

We used two metrics from OTIS to characterize transient storage in the five sample streams; the ratio of TSZ area to main channel area $\left(A_{s} / A\right)$ and mean storage residence time $\left(t_{\text {stor }}\right)$. The first metric, $A_{s} / A$, represents the relative size of the TSZ. Because $A_{s} / A$ does not incorporate the rate of exchange between the two zones, it does not reflect how long a given molecule spends in the storage zone. The second metric, $t_{\text {stor }}$ represents the average time that a water particle spends in storage and is calculated as:

$$
t_{\text {stor }}=\frac{1}{\alpha} \cdot \frac{A_{S}}{A},
$$

where $\alpha$ is the storage zone exchange coefficient, or the rate at which molecules move between the main channel and the TSZ. Thus, $t_{\text {stor }}$ incorporates both the size of the TSZ relative to the main channel and the exchange rate between the two zones (Zarnetske et al. 2007).

\section{Physical sorption}

Physical sorption of $\mathrm{P}$ in sediments from the five study streams was estimated following protocols outlined by Lottig \& Stanley (2007). At each stream, five sediment samples were collected along a longitudinal transect at $1 \mathrm{~m}$ intervals. Two samples were taken from the right side of the stream, two from the left, and one from the middle. Samples were collected in plastic resealable bags that were kept sealed until bags were submerged in sediments to reduce potential contamination by surface water and aquatic vegetation. Sediment samples were kept cool and out of direct sunlight until incubation. In addition, $10 \mathrm{~L}$ of water was collected from the top of the longitudinal transect for use in the incubation.

Sediment subsamples were pooled by stream and mixed thoroughly prior to incubations, which were conducted in triplicate for each stream, in 0.5 pint Mason jars. Into each jar, we mixed $30 \mathrm{~g}$ of sediment with $10 \mathrm{~mL}$ of site water. Half the jars were treated with $2 \mathrm{~mL}$ of a $37 \%$ formalin solution and shaken continuously for 30 minutes to kill the biological component of the sediments. Following this incubation, $100 \mathrm{~mL}$ of site water was added to killed and live jars. All jars (live and killed sediments) received a $\mathrm{PO}_{4}^{3}-$ spike with a target concentration of $2 \mathrm{mg} / \mathrm{L}$ and were incubated for two hours and shaken every 15 minutes. Initial and final nutrient samples were collected, filtered and analysed using the procedures described above. Phosphorus uptake by killed sediments was used to estimate physical sorption, while the difference in $\mathrm{P}$ uptake between live and killed sediments was used to estimate uptake due to biological processes.

\section{Statistical analysis}

All comparisons of means between upland and floodplain streams were conducted as two-sample Student's t-tests with three degrees of freedom, following tests for adherence to assumptions of normality and equal variances. Because of low sample sizes, we report two levels of significance. We adhere to the convention of using an alpha of 0.05 to determine statistical significance, but we also acknowledge our lack of statistical power with use of the term "marginally significant" for results with $P$ values that fall between 0.05 and 0.1 . To assess differences in relationships between TSZ metrics, stream discharge, and nutrient uptake metrics, we used linear regression analysis.

\section{Results}

\section{Background water chemistry}

Most physical and chemical characteristics were similar between upland and floodplain streams (Table 1). The exceptions were significantly higher mean concentrations of DOC $\left(17.5 \pm 0.6\right.$ vs. $\left.13.5 \pm 0.5 \mathrm{mg} \mathrm{L}^{-1} ; P=0.02\right)$ and DOC:DON $(37.8 \pm 1.04$ vs. $23.9 \pm 3.2 ; P=0.001)$, in upland streams, slightly higher iN:iP $\left[\left(\mathrm{NH}_{4}+\mathrm{NO}_{3}\right) / \mathrm{SRP}\right]$ in floodplain streams, which was marginally significant $(7.3 \pm 1.1$ vs. $3.3 \pm 0.9 ; P=0.06)$, and higher SRP in yedoma streams, although this difference was not statistically significant $\left(27 \pm 6.7\right.$ vs. $\left.14 \pm 4.5 \mu_{\mathrm{g} \mathrm{L}}^{-1} ; P=0.22\right)$.

In all streams, DON was the most abundant form of $\mathrm{N}$, with concentrations an order of magnitude higher than either $\mathrm{NH}_{4}$ or $\mathrm{NO}_{3}$. Inorganic $\mathrm{N}$ pools were dominated by $\mathrm{NH}_{4}\left(\mathrm{NH}_{4}: \mathrm{NO}_{3}>2\right)$, and $\mathrm{NO}_{3}$ concentrations were generally quite low (Table 1). Concentrations of SRP were more variable between streams, ranging from ca. 9 to $35 \mu \mathrm{g} \mathrm{L}^{-1}$, and N:P of the inorganic pool (iN:iP; Table 1) was generally low in all streams $(\leq 6.2)$.

\section{Whole-stream nutrient uptake}

Mean uptake lengths of $\mathrm{N}\left(S_{W N}\right)$ were much longer in floodplain streams than upland streams (455 and $81 \mathrm{~m}$, respectively; $P=0.006$; Fig. $2 \mathrm{a}$ ), while uptake lengths of $P$ were similar (31 and $52 \mathrm{~m}$, respectively; $P=0.43$; Fig. 2a). As a result, $S_{W N}: S_{W P}$ was much higher in floodplain 


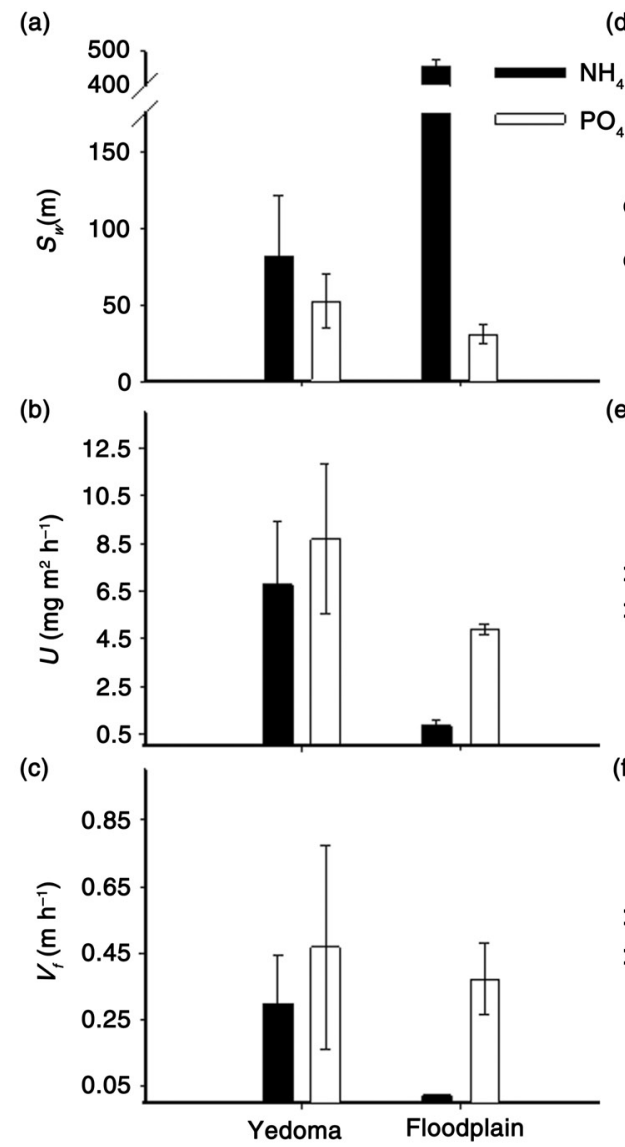

(d)
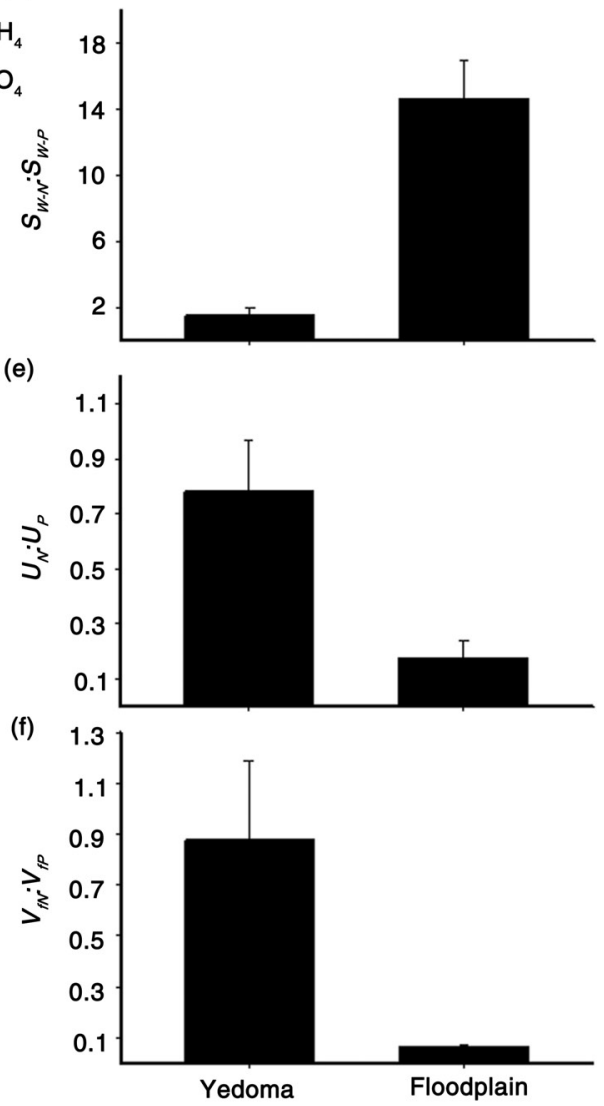

Fig. 2 Nutrient spiralling parameters $\left(S_{W}, U, v_{f}\right)$ for $(a-c) N$ and $P$ and $(d-f)$ their ratios in upland and floodplain streams. Error bars are \pm 1 standard error.

streams than upland streams (15 and 1.6, respectively; $P=0.005$; Fig. 2d). Results from both $U$ and $v_{f}$ showed a similar pattern to uptake lengths, although the differences were not statistically significant (Fig. 2b, c). In addition, $\mathrm{NO}_{3}$ concentrations did not increase significantly during any $\mathrm{NH}_{4}$ additions, suggesting nitrification rates were too low to explain longitudinal declines in $\mathrm{NH}_{4}$ concentrations in all streams. The ratios of $U_{N}: U_{P}$ and $v_{f N}: v_{f P}$ were higher in upland streams than floodplain streams, although these differences were only marginally significant $(P<0.1$; Fig. 2e, f). Within upland streams, statistical comparisons between spiralling metrics for $\mathrm{N}$ and $\mathrm{P}$ yielded no significant differences. In the floodplain streams, however, P uptake lengths were significantly lower than $\mathrm{N}$ uptake lengths $(P=0.003$, Fig. 2a), and $U_{p}$ was significantly higher than $U_{N}(P=0.01$, Fig. $2 \mathrm{~b})$, while $v_{f P}$ was higher than $v_{f N}$ but this difference was only marginally significant $(P<0.1$, Fig. $2 c)$. Additionally, no spiralling metrics for either $\mathrm{N}$ or $\mathrm{P}$ were significantly related to discharge in either upland or floodplain streams.

\section{Transient storage modelling}

We found no significant differences when comparing means between upland and floodplain streams for either $A_{s} / A$ or $t_{\text {stor }}$; therefore, we used a regression approach to assess patterns in transient storage. Both $A_{s} / A\left(R^{2}=0.925\right.$, $P=0.025)$ and $t_{\text {stor }}\left(R^{2}=0.793, P=0.027\right)$ showed a strong negative relationship with discharge $(Q)$ across all streams (Fig. 3a, b). We also found negative relationships between $v_{f p}$ and both $A_{s} / A$ and $t_{\text {stor }}$ although these relationships were not statistically significant (Fig. 3c, d). It should be noted that $A_{S}$ and $t_{\text {stor }}$ could not be accurately modelled for stream FPS2 because of an instrument malfunction during solute addition. This malfunction did not affect our ability to assess nutrient spiralling metrics.

\section{P sorption}

In all sorption experiments, a high proportion (ca. 60$80 \%$ ) of added P was removed during incubation. Upland sediments showed a significantly higher proportion of 
(a)

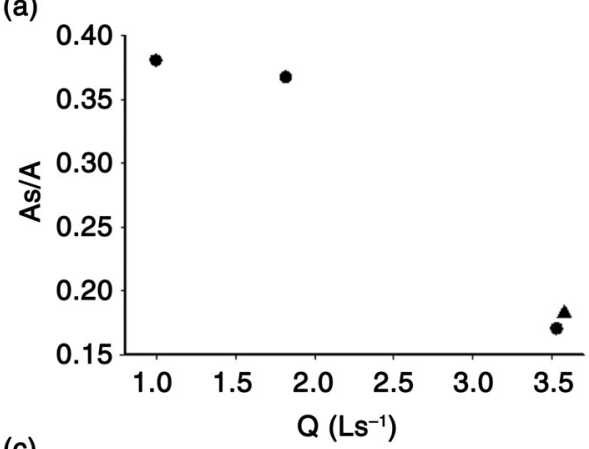

(c)

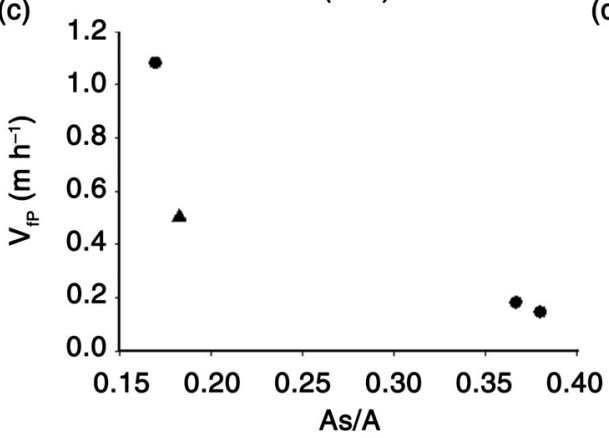

(b)

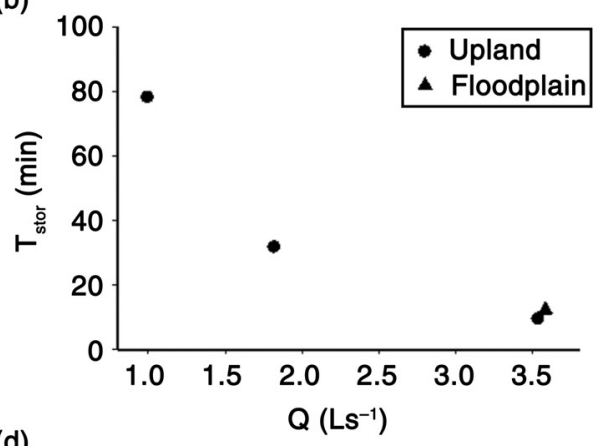

(d)

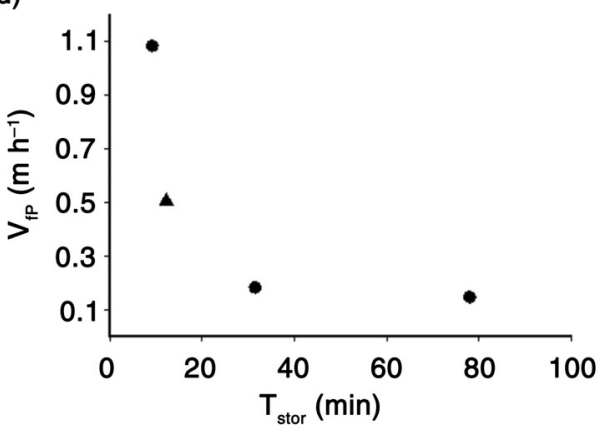

Fig. 3 Relationships between transient storage indices $\left(A_{s} / A\right.$ and $\left.t_{s t o r}\right)$ and $(a, b)$ discharge and $(c, d) v_{f P}$. Error bars are \pm 1 standard error.

biological uptake than floodplain sediments (18\% vs. $7 \%$ respectively; $P<0.05$; Fig. 4 ). Physical sorption, however, was responsible for a higher proportion of $P$ removal than biological uptake in all sediment experiments.

\section{Discussion}

\section{Nutrient spiralling metrics}

Our results clearly show that small streams in the Kolyma River basin have the potential to act as active processors of nutrients during summer months, but that there is significant landscape-scale variation in nutrient demand, which elements are being processed, and the relative importance of biological uptake. Specifically, our results highlight fundamental differences in how upland and floodplain streams process $\mathrm{N}$ and $\mathrm{P}$ inputs. $\mathrm{N}$ and $\mathrm{P}$ uptake lengths in upland streams were similar, while floodplain streams were characterized by relatively high $\mathrm{P}$ uptake and negligible $\mathrm{N}$ uptake (Fig. 2). One hypothesis for this observation is simply $\mathrm{P}$ limitation of floodplain streams, as has been observed in the Alaskan tundra (Peterson et al. 1985; Slavik et al. 2004). Alternatively, this pattern may be the result of high physical sorption of P (Lottig \& Stanley 2007) and low biological uptake of nutrients in floodplain streams relative to upland streams. Results of sorption experiments support this conclusion, suggesting that biological uptake of $\mathrm{P}$ in upland streams is threefold higher than in floodplain streams and that nearly all $\mathrm{P}$ uptake in floodplain streams was explained by physical processes (ca. 95\%, Fig. 4). In addition, we suggest that physical processes dominate $\mathrm{P}$ uptake, while $\mathrm{NH}_{4}$ uptake is likely to be a mix of physical and biological factors.

Differences in concentration and chemical composition of dissolved organic matter may contribute to variation in

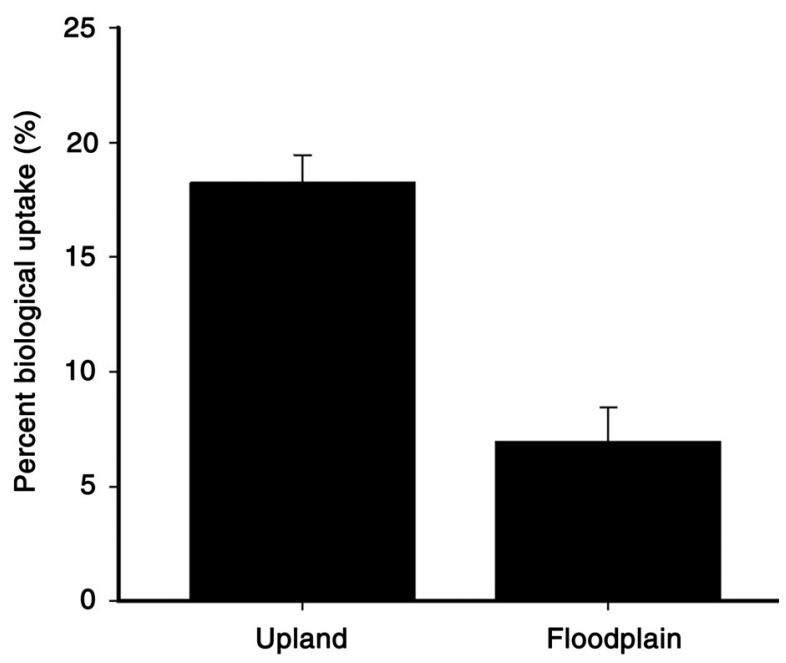

Fig. 4 Biological uptake of $\mathrm{P}$ by floodplain and upland sediments. Error bars are \pm 1 standard error. 
$\mathrm{N}$ uptake between upland and floodplain streams. All study streams were undersaturated with dissolved oxygen and showed high $\mathrm{NH}_{4}: \mathrm{NO}_{3}$, suggesting heterotrophic activity is likely to dominate stream metabolism. Concentrations of DOC are relatively high in all study streams (ca. 13-18 $\mathrm{mg} \mathrm{L}^{-1}$, Table 1) and could contribute substantially to heterotrophic metabolism, depending on its quality (Mann et al. 2012). Upland streams are roughly $30 \%$ higher in background DOC, and previous work has shown DOC in upland streams to be more labile (Mann et al. 2013). In addition, upland streams are ca. 35\% higher in DOC:DON, and ca. 55\% lower in iN:iP (Table 1) than floodplain streams. We suggest that these factors combined may contribute to higher $\mathrm{NH}_{4}$ demand in upland streams, but this remains quite speculative to date and should be viewed with caution.

In contrast to $\mathrm{N}$ uptake, $\mathrm{P}$ uptake did not differ between upland and floodplain streams, and, as discussed above, is likely explained by physical sorption. Overall, our results suggest that sediment characteristics that influence P sorption and hydrologic variables that influence how water and sediments interact are likely to be important for understanding how streams will process materials entering from the surrounding watershed. Indeed the relationship between transient storage and $\mathrm{P}$ uptake (see below) highlights the importance of understanding hydrologic exchange between surface and sediments (see also Greenwald et al. 2008).

\section{Transient storage and nutrient uptake}

Transient storage dynamics of Siberian Arctic streams are comparable to those in streams in other regions. The average $A_{S} / A$ for our study streams was ca. 0.24 , similar to a range of $0.2-0.6$ reported for temperate streams (D'Angelo et al. 1993; Harvey et al. 2003), and to values of 0.31 and 0.32 reported for similar small Arctic streams in Alaska (Edwardson et al. 2003, Zarnetske et al. 2007). We also found an inverse relationship between transient storage $\left(t_{\text {stor, }} A_{s} / A\right)$ and discharge $(Q)$, consistent with previous studies (D'Angelo et al. 1993; Edwardson et al. 2003; Zarnetske et al. 2008) that suggest that frozen active layer soils and, in some cases, shallow permafrost can act as barriers to deeper hyporheic exchange with groundwater aquifers. This may result in increased flushing of surface features when discharge increases, particularly during early spring and summer thaw, which may reduce hydrologic residence time in TSZs.

Our results also suggest that transient storage is affecting $\mathrm{P}$ processing rates (Fig. 3c, d). Although uncommon, our observation of a negative relationship between both $t_{s t o r}$ and $A_{s} / A$ and $v_{f P}$ is consistent with other work that found the TSZ to be less active in terms of nutrient uptake relative to the main channel (Valett et al. 2002), although the explanation for these results remains unclear. Our data are not extensive enough to contribute substantially to a mechanistic understanding of this pattern, and more data are required to confirm the generality of our result. A better, more mechanistic, understanding of the drivers of nutrient dynamics in streams of this region represents a priority for future research.

\section{Implications}

The consequences of increased input of nutrients from permafrost thaw for aquatic food webs and nutrient transport are likely to be quite different for floodplain versus upland streams, particularly if physical processes, rather than biological uptake, dominate nutrient loss from the water column to a greater degree in the floodplain. It seems quite likely that increasing organic matter and nutrient inputs will stimulate biological activity to a greater degree than physical processes (Lottig \& Stanley 2007), which may lead to larger changes in organic matter and nutrient dynamics in upland streams. This may result in very different spatial and temporal patterns in nutrient export downstream. Indeed, our results suggest strong differences in the ratio of $\mathrm{N}$ uptake to $\mathrm{P}$ uptake between upland and floodplain streams that are likely the result of differences in the relative importance of biological and physical processes (Fig. 2d-f).

These data provide a preliminary understanding of $\mathrm{N}$ and $\mathrm{P}$ uptake in stream ecosystems in the Siberian Arctic. While these findings are only a snapshot of how these streams function in a highly seasonal and variable environment, they represent a first look at these processes during low-flow summer months when streams are the most active and their influence on downstream nutrient fluxes is likely to be near its maximum. Multi-year data sets that measure these processes over multiple seasons and flow conditions are necessary to fully understand $\mathrm{N}$ and $\mathrm{P}$ cycling. Despite the limited data set reported here, we have provided a substantial first step towards understanding stream biogeochemistry in an understudied yet critically important region of the world.

\section{Acknowledgements}

This research was funded by the Polaris Project (ARC1044612), and we are grateful to all Polaris Project participants for stimulating discussion and help with field and laboratory activities. We especially thank Greg Fiske at the Woods Hole Research Center for the map in Fig. 1. We are also grateful to three anonymous reviewers for 
insightful comments that substantially improved the quality of the manuscript.

\section{References}

Alexander R.B., Smith R.A. \& Schwarz G.E. 2000. Effects of stream channel size on the delivery of nitrogen to the Gulf of Mexico. Nature 403, 758-761.

Benstead J.P., Deegan L.A., Peterson B.J., Huryn A.D., Bowden W.B., Suberkropp K., Buzby K.M., Green A.C. \& Vacca J. 2005. Responses of a beaded Arctic stream to shortterm N and P fertilization. Freshwater Biology 50, 277-290.

Corradi C., Kolle O., Walter K., Zimov S.A. \& Schulze E.D. 2005. Carbon dioxide and methane exchange of a northeast Siberian tussock tundra. Global Change Biology 11, 1910-1925.

D'Angelo D., Webster J., Gregory S. \& Meyer J. 1993. Transient storage in Appalachian and Cascade mountain streams as related to hydraulic characteristics. Journal of the North American Benthological Society 12, 223-235.

Edwardson K.J., Bowden W.B., Dahm C. \& Morrice J. 2003. The hydraulic characteristics and geochemistry of hyporheic and parafluvial zones in Arctic tundra streams, North Slope, Alaska. Advances in Water Resources 26, 907-923.

Ensign S.H. \& Doyle M.W. 2006. Nutrient spiraling in streams and river networks. Journal of Geophysical ResearchBiogeosciences 111, G04009, doi: http://dx.doi.org/10.1029/ 2005JG000114

Finlay J., Neff J., Zimov S., Davydova A. \& Davydov S. 2006. Snowmelt dominance of dissolved organic carbon in high-latitude watersheds: implications for characterization and flux of river DOC. Geophysical Research Letters 33, L10401, doi: http://dx.doi.org/10.1029/2006GL025754

Frey K.E. \& McClelland J.W. 2009. Impacts of permafrost degradation on Arctic river biogeochemistry. Hydrological Processes 23, 169-182.

Greenwald M.J., Bowden W.B., Gooseff M.N., Zarnetske J.P., McNamara J.P., Bradford J.H. \& Brosten T.R. 2008. Hyporheic exchange and water chemistry of two Arctic tundra streams of contrasting geomorphology. Journal of Geophysical Research-Biogeosciences 113, G02029, doi: http:// dx.doi.org/10.1029/2007JG000549

Harvey J., Conklin M. \& Koelsch R. 2003. Predicting changes in hydrologic retention in an evolving semi-arid alluvial stream. Advances in Water Resources 26, 939-950.

Hoellein T.J., Tank J.L., Rosi-Marshall E.J., Entrekin S.A. \& Lamberti G.A. 2007. Controls on spatial and temporal variation of nutrient uptake in three Michigan headwater streams. Limnology and Oceanography 52, 1964-1977.

Holmes R.M., McClelland J.W., Raymond P.A., Frazer B.B., Peterson B.J. \& Stieglitz M. 2008. Lability of DOC transported by Alaskan rivers to the Arctic Ocean. Geophysical Research Letters 35, L03402, doi: http://dx.doi.org/10.10289/ 2007GL032837

Holmes R.M., Minot A., KéRouel R., Hooker B.A. \& Peterson B.J. 1999. A simple and precise method for measuring ammonium in marine and freshwater ecosystems. Canadian Journal of Fisheries and Aquatic Science 56, 1801-1808.

Lottig N.R. \& Stanley E.H. 2007. Benthic sediment influence on dissolved phosphorus concentrations in a headwater stream. Biogeochemistry 84, 297-309.

Mann P.J., Davidova A., Zimov N., Spencer R.G.M., Davydov S., Bulygina E., Zimov S. \& Holmes R.M. 2012. Controls on the composition and liability of dissolved organic matter in Siberia's Kolyma River Basin. Journal of Geophysical Research—Biogeosciences 117, G01028, doi: http://dx.doi.org/ 10.1029/2011JG001798

Mann P.J., Sobczak W., LaRue M., Bulygina E., Davydova A., Vonk J.E., Schade J., Davydov S., Zimov N., Holmes R.M. \& Spencer R.G.M. 2013. Evidence for key enzymatic controls on metabolism of Arctic river organic matter. Global Change Biology 20, 1089-1100.

Mulholland P.J., Helton A.M., Poole G.C., Hall R.O., Hamilton S.K., Peterson B.J. \& Tank J.L. 2008. Stream denitrification across biomes and its response to anthropogenic nitrate loading. Nature 452, 202-205.

Newbold J.D. 1992. Cycles and spirals of nutrients. In P. Calow \& G.E. Petts (eds.): The rivers handbook. Pp. 370-408. Oxford: Blackwell Scientific.

Newbold J.D., Elwood J.W., O'Neill R.V. \& Sheldon A.L. 1983. Phosphorus dynamics in a woodland stream ecosystem: a study of nutrient spiraling. Ecology 64, 1249-1265.

Newbold J.D., Elwood J.W., O'Neill R.V. \& Van Winkle W. 1981. Measuring nutrient spiraling in streams. Canadian Journal of Fisheries and Aquatic Sciences 38, 860-863.

Peterson B.J., Hobbie J.E., Hershey A., Lock M., Ford T., Vestal R., Hullar M., Ventullo R. \& Volk G. 1985. Transformation of a tundra river from heterotrophy to autotrophy by addition of phosphorus. Science 229, 1383-1386.

Runkel R.L. 1998. One dimensional transport with inflow and storage (OTIS): a solute transport model for streams and rivers. Water-Resources Investigation Report 98-4018. Denver: US Geological Survey.

Salehin M., Packman A.I. \& Worman A. 2003. Comparison of hyporheic exchange in vegetated and unvegetated reaches of a small agricultural stream in Sweden: seasonal variation and anthropogenic manipulation. Advanced Water Resources 26, 951-964.

Schade J.D., MacNeill K., Thomas S.A., Mcneely F.C., Welter J.R., Hood J., Goodrich M., Power M.E. \& Finlay J.C. 2011. The stoichiometry of nitrogen and phosphorus spiraling in heterotrophic and autotrophic streams. Freshwater Biology $56,424-436$.

Schaefer K., Zhang T., Bruhwiler L. \& Barrett A.P. 2011. Amount and timing of permafrost carbon release in response to climate warming. Tellus Series B 63, 165-180.

Schuur E.A.G., Bockheim J., Canadell J.G., Euskirchen E., Field C.B., Goryachkin S.V., Hagemann S., Kuhry P., Lafleur P.M., Lee H., Mazhitova G., Nelson F.E., Rinke A., Romanovsky V.E., Shiklomanov N., Tarnocai C., Venevsky S., Vogel J.G. \& Zimov S.A. 2008. Vulnerability of permafrost carbon to climate change: implications for the global carbon cycle. BioScience 58, 701-714. 
Screen J.A. \& Simmonds I. 2010. The central role of diminishing sea ice in recent Arctic temperature amplification. Nature 464, 1334-1337.

Serreze M.C. \& Francis J.A. 2006. The Arctic on the fast track of change. Weather 61, 65-69.

Slavik K., Peterson B.J., Deegan L.A., Bowden W.B., Hershey A.E. \& Hobbie J.E. 2004. Long-term responses of the Kuparuk River ecosystem to phosphorus fertilization. Ecology 85, 939-954.

Sobczak W.V. \& Findlay S. 2002. Variation in bioavailability of dissolved organic carbon among stream hyporheic flowpaths. Ecology 83, 3194-3209.

Stream Solute Workshop 1990. Concepts and methods for assessing solute dynamics in stream ecosystems. Journal of the North American Benthological Society 9, 95-119.

Symon C., Arris L. \& Heal B. (eds.): 2005. Arctic climate impact assessment. Cambridge: Cambridge University Press.

Tarnocai C., Canadell J.G., Schuur E.A.G., Kuhry P., Mazhitova G. \& Zimov S. 2009. Soil organic carbon pools in the northern circumpolar permafrost region. Global Biogeochemical Cycles 23, GB2023, doi: http://dx.doi.org/10.1029/2008 GB003327

Taylor B.W., Keep C.A., Flecker A.S., Hall R.O., Jr., Koch B.J., Tronstad L.M. \& Ulseth A.J. 2007. Improving the fluorometric ammonium method: matrix effects, background fluorescence, and standard additions. Journal of the North American Benthological Society 26, 167-177.

Valett H., Crenshaw C. \& Wagner P. 2002. Stream nutrient uptake, forest succession, and biogeochemical theory. Ecology 83, 2888-2901.

Valett H.M., Thomas S.A., Mulholland P.J., Webster J.R., Dahm C.N., Fellows C.S., Crenshaw C.L. \& Peterson
C.G. 2008. Endogenous and exogenous control of ecosystem function: N cycling in headwater streams. Ecology 89, 3515-3527.

Vonk J.E., Mann P.J., Davydov S., Davydova A., Spencer R.G.M., Schade J.D., Sobczak W.V., Zimov N., Zimov S.A., Bulygina E., Eglinton T.I. \& Holmes R.M. 2013. High biolability of ancient permafrost carbon upon thaw. Geophysical Research Letters 40, 2689-2693.

Webster J.R. \& Patten B.C. 1979. Effects of watershed perturbation on stream potassium and calcium dynamics. Ecological Monographs 49, 51-72.

Wollheim W.M., Peterson B.J., Deegan L.A., Hobbie J.E., Hooker B., Bowden W.B., Edwardson K.J., Arscott D.B. \& Hershey A.E. 2001. Influence of stream size on ammonium and suspended particulate nitrogen processing. Limnology and Oceanography 46, 1-13.

Zarnetske J.P., Gooseff M.N., Bowden W.B., Greenwald M.J. \& Brosten T.R. 2008. Influence of morphology and permafrost dynamics on hyporheic exchange in Arctic headwater streams under warming climate conditions. Geophysical Research Letters 35, L02501, doi: http://dx.doi.org/10.1029/ 2007GL032049

Zarnetske J.P., Gooseff M.N., Brosten T.R., Bradford J.H., McNamara J.P. \& Bowden W.B. 2007. Transient storage as a function of geomorphology, discharge, and permafrost active layer conditions in Arctic tundra streams. Water Resources Research 43, W07410, doi: http://dx.doi.org/10. 1029/2005WR004816

Zimov S.A., Schuur E.A.G. \& Chapin F.S. III 2006. Climate change: permafrost and the global carbon budget. Science $312,1612-1613$. 